Check for updates

Cite this: RSC Adv., 2018, 8, 17813

Received 26th February 2018

Accepted 23rd April 2018

DOI: $10.1039 / c 8 r a 01659 c$

rsc.li/rsc-advances

\section{Synergistic effect of graphene and silicon dioxide hybrids through hydrogen bonding self-assembly in elastomer composites $\uparrow$}

\author{
Shuai Zhao, ${ }^{*}$ Shicheng Xie, Peipei Sun, Zheng Zhao, Lin Li, (D) * Xiaoming Shao, \\ Xiaolin Liu and Zhenxiang Xin
}

A novel graphene-silicon dioxide hybrid (HGS) was prepared by plant polyphenol-tannic acid (TA) functionalized pristine graphene (G-TA) and primary amine-containing silane coupling agent modified $\mathrm{SiO}_{2}\left(\mathrm{Si}-\mathrm{NH}_{2}\right)$. Through strong hydrogen-bonding interaction between the phenolic hydroxyl groups on $\mathrm{G}-\mathrm{TA}$ and primary amine groups on $\mathrm{Si}-\mathrm{NH}_{2}, \mathrm{SiO}_{2}$ was uniformly loaded to the surface of graphene. Due to the synergistic dispersion effect of graphene and $\mathrm{SiO}_{2}$, which prevents restacking and re-aggregating of both graphene and $\mathrm{SiO}_{2}$, HGS hybrids were distributed evenly in the natural rubber (NR) matrix (HGS@NR). Simultaneously, the surface roughness of graphene after loading $\mathrm{SiO}_{2}$ and the interfacial interaction between the HGS hybrid and NR matrix were substantially improved. Due to the good dispersion and strong interface, the overall properties of HGS@NR nanocomposites are drastically enhanced compared with those of GS@NR nanocomposites prepared by dispersing the blend of unmodified graphene and $\mathrm{SiO}_{2}$ (GS) in NR. The HGS@NR nanocomposites possess the highest tensile strength up to $27.8 \mathrm{MPa}$ at $0.5 \mathrm{wt} \%$ and tear strength of $60.2 \mathrm{MPa}$ at $0.5 \mathrm{wt} \%$. Thermal conductivities of the HGSaNR nanocomposites were found to be 1.5 -fold better than that of the GSaNR nanocomposites. Also, the HGS@NR nanocomposites exhibit excellent abrasive resistant capacity that is nearly 2 -fold better than that of the GSCNR nanocomposites. These results suggest that HGS has great potential in high-performance nanocomposites and a new strategy of constructing the efficient graphene- $\mathrm{SiO}_{2}$ hybrid fillers has been established.

\section{Introduction}

High performance and superior interface interaction are always significant in polymer science and engineering, and stimulate numerous diverse applications of polymers. Generally, a single filler could not meet the variety of performance requirements of polymer products. Meanwhile, the fillers in a composite material system usually are poorly compatible with the polymer matrix. Recently, a hybrid filler consisting of two or more constituents with different performance and functions offers an alternative and novel inspiration for designing highperformance or functional polymer nanocomposites. ${ }^{1-4}$ Due to the specific interactions between different fillers, hybrid systems act with a positive synergistic effect on the overall performance of polymer nanocomposites. ${ }^{2,5-7}$

Key Laboratory of Rubber-Plastics, Ministry of Education, Shandong Provincial Key Laboratory of Rubber-Plastics, School of Polymer Science and Engineering, Qingdao University of Science and Technology, Qingdao 266042, China. E-mail: lyzhsh@163. com; qustlilin@163.com

$\uparrow$ Electronic supplementary information (ESI) available. See DOI: 10.1039/c8ra01659c
Nowadays graphene is widely used as functional filler in polymer nanocomposites for its extraordinary mechanical, thermal and electrical properties. ${ }^{8-10}$ Graphene can cause a crucial improvement in the electrical, mechanical, and thermal properties of the resulting graphene/polymer composites at very low doping percentages. However, graphene is an atomically thin nano-plate of $\mathrm{sp}^{2}$ bonded carbon atoms. It is a processing challenge for these hydrophobic fillers to be uniformly dispersed in the polymer matrix. Excellent dispersions and interfacial interactions between graphene and the polymers are vital to the generation and utilization of a strong composite. ${ }^{11}$ The prevalent strategy to intensify interactions between graphene and the polymer chains is chemical functionalization of the surface of the nanoparticles. ${ }^{12}$ However, the chemical functionalization strategies are extraordinary comprehensive and poor universal applicability, destruction of graphene intrinsic properties and that the interfaces interaction between graphene and the polymer chains is not obvious.

Recently, various hybrid combinations based on graphene have been supposed to be ideal candidates to construct hybrid fillers towards high-performance polymer nanocomposites. Metal oxides $\left(\mathrm{TiO}_{2}, \mathrm{SnO}_{2}, \mathrm{Fe}_{3} \mathrm{O}_{4}\right) /$ graphene hybrids have been widely investigated as promising high-capacity anode material 
for lithium-ion batteries. ${ }^{\mathbf{1 3 , 1 4}}$ A facile ionic self-assembly process has constructed two-dimensional graphene/ $\mathrm{SnO}_{2} /$ graphene hybrids with $\mathrm{SnO}_{2}$ nanoparticles sandwiched in graphene sheets. ${ }^{\mathbf{1 5}}$ A nanocomposite comprised of chemically converted graphene and carbon nanotubes can preserve the intrinsic electronic and mechanical properties of both components. ${ }^{16}$ Baochun Guo et al. have systematically investigated the mechanism for the synergistic reinforcement in an elastomer reinforced by nanocarbon hybrids consisting of $2 \mathrm{D}$ reduced graphene oxide and 1D carbon nanotubes. ${ }^{17}$

While these achievements are quite impressive, synergistic effect of graphene and silicon dioxide $\left(\mathrm{SiO}_{2}\right)$ hybrids in elastomer composites is still less research. $\mathrm{SiO}_{2}$ applied in composites have attracted much research attention ${ }^{\mathbf{1 8 - 2 2}}$ in the last few decades owing to the superior properties of $\mathrm{SiO}_{2}$ nanoparticles such as toughness, tensile strength, thermal stability, gas separation performance, high scattered performance, and thermal resistance ${ }^{23}$ and they have various applications in high-performance coatings, ${ }^{24,25}$ fibers, ${ }^{26,27}$ bioactive polymers, ${ }^{28,29}$ rubber composites etc. ${ }^{30-32}$ The nanometer-sized $\mathrm{SiO}_{2}$ particles are used not only as a kind of filler, but also as reinforcing ${ }^{33,34}$ and toughening ${ }^{35}$ agents that can impart good mechanical properties, thermal stability, and toughness, as well as magnetic and optical properties to the polymers. However, it is usually hard to assure the uniform distribution of $\mathrm{SiO}_{2}$ because of its poor interaction with the organic matrix, which gives rise to poor stability of nanocomposites. Therefore, the strong interface adhesion between the organic matrix and $\mathrm{SiO}_{2}$ nanoparticles is a key to the application of $\mathrm{SiO}_{2}$ nanoparticles as fillers. Ming Tian et al. have prepared graphene oxide (GO)encapsulated $\mathrm{SiO}_{2}$ hybrids via electrostatic self-assembly. The as-prepared hybrids were introduced into polydimethylsiloxane (PDMS) elastomer to simultaneously increase the dielectric constant $(k)$ and mechanical properties of PDMS. ${ }^{36}$

$\mathrm{SiO}_{2} /$ reduced graphene oxide hybrids were fabricated by an electrostatic assembly. ${ }^{37}$ The results revealed the better dispersion of hybrid filler and stronger interfacial interaction in the SBR and hybrid filler by contrast with those of $\mathrm{SBR} / \mathrm{SiO}_{2}$ and $\mathrm{SBR} /$ reduced graphene oxide, contributes to the significant enhancement in the mechanical performances of composites. The achievement is quite significant. However, the hybrid filler system refers to $\mathrm{SiO}_{2}$ and reduced graphene oxide. Environmental pollution and performance damage of the preparation method for reduced graphene oxide limit its application greatly. Therefore, the research questions related to the synergistic effect of graphene and $\mathrm{SiO}_{2}$ hybrids in elastomer composites that need to be addressed.

In this study, we aim to prepare a novel graphene- $\mathrm{SiO}_{2}$ hybrid (HGS) by a hydrogen-bonding assembly in favor of overcoming the aggregation of the individual graphene sheet

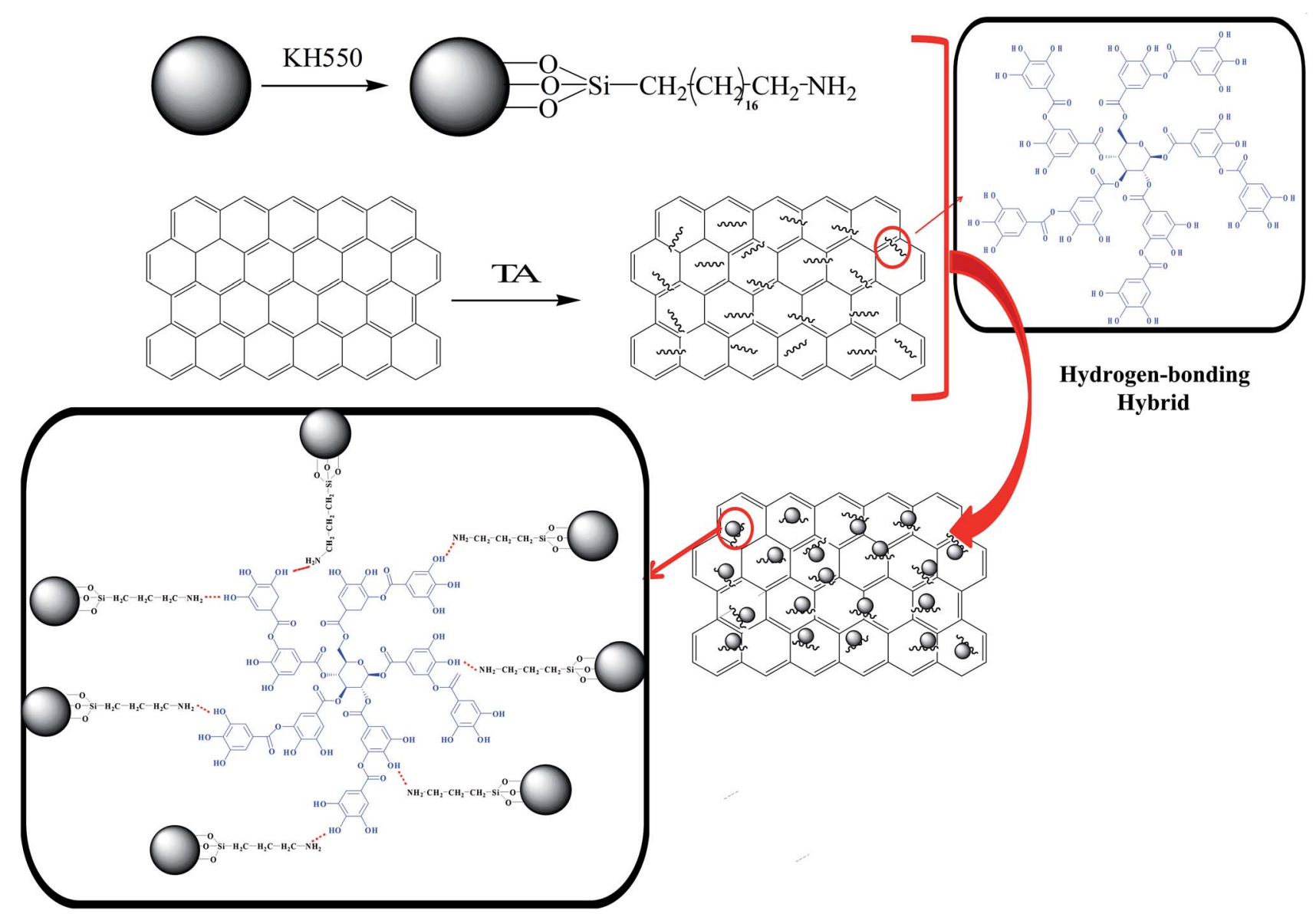

Scheme 1 Schematic illustration of the synergistic hybridization graphene- $\mathrm{SiO}_{2}$ filler. 
and $\mathrm{SiO}_{2}$ nanoparticle; a schematic illustration is shown in Scheme 1. And subsequently, HGS was incorporated into NR to fabricate NR composites. It is effortless to guarantee not only the uniform distribution of HGS because of the synergistic disperse effect of graphene and $\mathrm{SiO}_{2}$ by a hydrogen-bonding assembly, but also the strongly interfacial interaction between HGS and polymer due to the increased surface roughness of graphene after loading $\mathrm{SiO}_{2}$. Furthermore, the intrinsic performances of graphene for G-TA are maintained well due to the physical interaction between graphene and TA. The overall performances of HGS@NR nanocomposites are improved drastically compared with that of nanocomposites prepared by dispersing the blend of GS in NR, proving the importance of the strong hydrogen-bonding interaction between phenolic hydroxyl groups on G-TA and primary amine groups on $\mathrm{Si}-\mathrm{NH}_{2}$. As a result, the HGS@NR nanocomposites possess the highest tensile strength up to $27.8 \mathrm{MPa}$ at $0.5 \mathrm{wt} \%$ and tear strength 60.2 MPa at $0.5 \mathrm{wt} \%$. Thermal conductivities of the HGS@NR nanocomposites were found nearly 1.5 -fold better than that of the NR/HGS nanocomposites. The HGS@NR nanocomposites exhibit excellent abrasive resistant capacity with nearly 2 -fold better than that of the GS@NR nanocomposites.

\section{Experimental}

\subsection{Materials}

Graphene was supplied by the sixth element (Changzhou) material technology Co. Ltd. (China). Submicron-sized $\mathrm{SiO}_{2}$ (average diameter: $300 \mathrm{~nm}$ ) was supplied by Degussa AG (Germany). $\gamma$-Aminopropyltriethoxysilane (KH550) was purchased from Sigma-Aldrich Technology Co., LTD (China). Plant polyphenol-tannic acid (TA) was purchased from Aladdin Technology Co., LTD (China). NR was provided by Sanlux Co., Ltd (China). Zinc oxide, stearic acid, $N$-isopropyl- $N$-phenyl- $p$-phenylenediamine (4010NA), 2-benzothiazolyl disulfide (DM) and $N$-cyclohexyl-2-benzothiazole sulfenamide (CZ) were provided by Sanlux Co., Ltd (China).

\subsection{Hydrophobic modification of $\mathrm{SiO}_{2}$ particles}

The $\mathrm{SiO}_{2}$ particles were modified with silane coupling agent $\gamma$ aminopropyltriethoxysilane, KH550. ${ }^{38}$ The mass ratio of coupling agents relative to $\mathrm{SiO}_{2}$ is $0: 20,1: 20,2: 20$ and $3: 20$. Under vigorous stirring (5000 rpm), a dosage of coupling agents $(0 \mathrm{~g}, 1 \mathrm{~g}, 2 \mathrm{~g}$ and $3 \mathrm{~g}$ ) was respectively dispersed with a mixture solvent ( $1 \mathrm{~mL}$ deionized water and $10 \mathrm{~mL}$ ethanol) and added into four different three-necked round-bottom flasks. The reaction was carried out at $50{ }^{\circ} \mathrm{C}$ for $30 \mathrm{~min}$ for the completion of the hydrolysis reaction. Then a fixed mass $\mathrm{SiO}_{2}(20 \mathrm{~g})$ was respectively added into the four three-necked round-bottom flasks mentioned above and vigorously stirred at $5000 \mathrm{rpm}$ at $60{ }^{\circ} \mathrm{C}$ for $3 \mathrm{~h}$. The silane coupling agents modified $\mathrm{SiO}_{2}$ nanoparticles were washed with ethanol for three times after the centrifugation separation. The white powder was dried in a vacuum oven at $40{ }^{\circ} \mathrm{C}$ for $12 \mathrm{~h}$ and designed as $0 \mathrm{~S}, 1 \mathrm{~S}, 2 \mathrm{~S}$, and $3 \mathrm{~S}$.

\subsection{Preparation of graphene- $\mathrm{SiO}_{2}$ hybrid}

$3 \mathrm{~g}$ of graphene was added into a vial containing $30 \mathrm{~mL}$ TA aqueous solution which the concentration of TA is $0.05 \mathrm{~g} \mathrm{~mL}^{-1}$. The mixture was then sonicated for $30 \mathrm{~min}$ in a $30-35{ }^{\circ} \mathrm{C}$ water bath using a bath sonicator (Elmasonic E30H, $40 \mathrm{~W}, 37 \mathrm{kHz}$ ) to prepare TA functionalized graphene. Then TA functionalized graphene disperse is equally divided into triplicate. Subsequently, all the above prepared $1 \mathrm{~S}, 2 \mathrm{~S}$ and $3 \mathrm{~S}$ was respectively added to the three TA functionalized graphene aqueous solution with the same volume, and then the mixtures were sonicated in a $30-35{ }^{\circ} \mathrm{C}$ water bath for $1 \mathrm{~h}$ and designed as H1GS, H2GS, H3GS respectively. For comparison purpose, a sample of unmodified graphene- $\mathrm{SiO}_{2}$ hybrid (designed as GS) was prepared from oS and unmodified graphene subjecting to the same procedures that were used to prepare H1GS.

\subsection{Preparation of rubber/graphene- $\mathrm{SiO}_{2}$ hybrid composites}

Composite was performed in a $200 \mathrm{~mL}$ Banbury mixer at a rotor speed of $60 \mathrm{rpm}$ for the mixing stage at a temperature of $120^{\circ} \mathrm{C}$. The NR was fed into the mixer and premixed for $2 \mathrm{~min}$. This was followed by the sequential addition of zinc oxide ( $5 \mathrm{phr})$, stearic acid (3 phr), 4010NA (3 phr), DM (0.1 phr) and CZ (1.4 phr) and mixing the compounding ingredients for another $4 \mathrm{~min}$. Next our above prepared graphene-SiO $\mathrm{S}_{2}$ hybrid fillers (H1GS) was all added and compounded into the rubber for $3 \mathrm{~min}$ and then the mixture was discharged onto a two roll mill at $80{ }^{\circ} \mathrm{C}$ and designed as H1GS@NR, where the sulfur (2.8 phr) was added. H2GS@NR and H3GS@NR were prepared from H2GS, H3GS and NR subjecting to the same procedures that were used to prepare H1GS@NR. For comparison purpose, a sample of NR/ unmodified graphene- $\mathrm{SiO}_{2}$ hybrid composite (designed as GS@NR) was prepared from GS and NR subjecting to the same procedures that were used to prepare H1GS@NR.

\subsection{Characterization}

The infrared spectra were obtained with a Bruker Vertex 70 variable temperature Fourier Transform Infrared Spectrometer. Zeta potential ( $\zeta)$ was measured on a Malvern Zetasizer Nano-ZS system equipped with a $632.8 \mathrm{~nm}$ He-Ne laser. Thermogravimetric analysis was performed with a TGA 209 F1 instrument (NETZSCH) with a heating rate of $10{ }^{\circ} \mathrm{C} \mathrm{min}^{-1}$ under nitrogen purging. X-ray diffraction (XRD) pattern was recorded on a Rigaku D-MAX2500-PC diffractometer. Transmission electron microscopy (TEM) images were obtained using a JEM-2100 microscope. Scanning electron microscopy (SEM) was performed with JEOL-JSM-7500F microscopy. Dynamic mechanical analysis was performed on a DMA242 machine (NETZSCH) in tensile mode with a temperature increment of $3{ }^{\circ} \mathrm{C} \mathrm{min}^{-1}$. Dynamic rheological tests were used to measure the dynamic viscoelastic properties of hybrid nanocomposites by Rubber Processing Analyzer (RPA 2000, Alpha Technologies) with strain sweeps performed from $0.25 \%$ to $125 \%$ at a frequency of $1 \mathrm{~Hz}$ and at a temperature of $333 \mathrm{~K}$. The thermal conductivity was measured by a laser flash system (LFA 447 NanoFlash). Tensile and tear testing were carried out using an AI-7000S Universal 
Material Tester, with a dumbbell specimen at a tensile speed of $500 \mathrm{~mm} \mathrm{~min}^{-1}$ according to ISO 528:2009. Compression temperature rise and compression set are determined at $55{ }^{\circ} \mathrm{C}$ using rubber compression heat tester. The abrasion test was carried out with the Akron abrader according to GT-7012-A. The abrasion was defined as a volumetric loss of a strip sample.

\section{Results and discussion}

\subsection{The chemical structure of $\mathrm{Si}-\mathrm{NH}_{2}$ and G-TA}

The FTIR spectra of $0 \mathrm{~S}, 1 \mathrm{~S}, 2 \mathrm{~S}$ and $3 \mathrm{~S}$, are shown in Fig. 1. The peak at $1107 \mathrm{~cm}^{-1}$ [Fig. $\left.1(0 \mathrm{~S})\right]$ corresponds to the asymmetric stretching vibration of $\mathrm{Si}-\mathrm{O}-\mathrm{Si}$, and the peak at $3423 \mathrm{~cm}^{-1}$ is the characteristic absorption peak of $-\mathrm{OH}$ groups. Compared with 0S, the FTIR spectrum in [Fig. 1 (1S, 2S, 3S)] shows that the peak at $2929 \mathrm{~cm}^{-1}$ corresponds to the asymmetric stretching vibration of $-\mathrm{CH}_{2}$, and the peaks at $1453 \mathrm{~cm}^{-1}$ correspond to the asymmetric bending vibration of $-\mathrm{CH}_{2}$, respectively, indicating that KH550 is successfully grafted onto $\mathrm{SiO}_{2}$. Moreover, the strong peak at $1640 \mathrm{~cm}^{-1}(\mathrm{OS})$ which is attributed to the bending vibration of $\mathrm{H}_{2} \mathrm{O}$ is represented weaker and weaker for $1 \mathrm{~S}, 2 \mathrm{~S}$

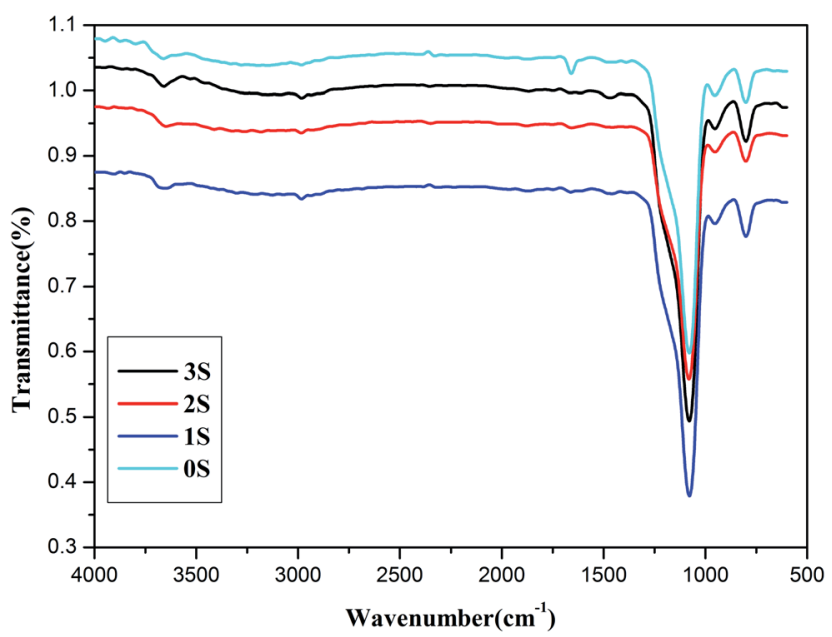

Fig. 1 FTIR spectrum of OS, 1S, 2S and 3S.

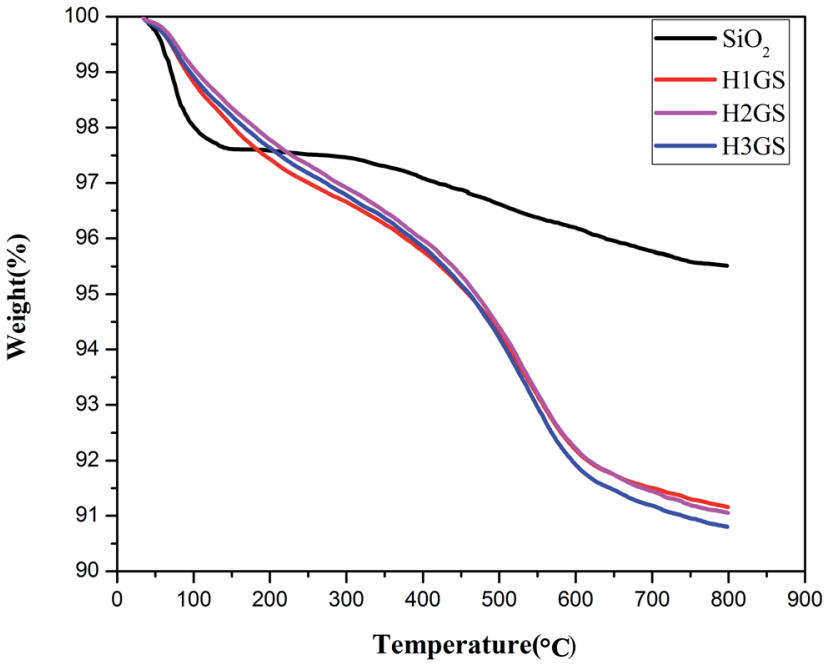

Fig. 3 TGA graph of H1GS, H2GS and H3GS.

and 3S. It indicated that the hydrophobicity of $\mathrm{SiO}_{2}$ after modified with KH550 becomes strong. Just the FTIR spectra of $3 \mathrm{~S}$ show that the double peaks between $3300 \mathrm{~cm}^{-1}$ to $3500 \mathrm{~cm}^{-1}$ which represent the characteristic absorption peaks for the stretching vibration of the primary amine group. It can be expected that the strong signal peaks of $\mathrm{SiO}_{2}$ mask the much weaker signal peaks of primary amine group due to low grafting degree.

To make clear the interaction between TA and graphene, FTIR has been performed to characterize the obtained G-TA hybrid. As illustrated in the FTIR spectra in Fig. 2a, compared with the spectrum of TA, G-TA has a similar spectrum with TA, no new signal peaks appear, but the characteristic peaks of TA such as $\mathrm{O}-\mathrm{H}$ bending vibration $\left(1310 \mathrm{~cm}^{-1}\right)$, aromatic ring breathing vibration (1640 and $1525 \mathrm{~cm}^{-1}$ ), are significantly blue shifted to 1383,1670 and $1570 \mathrm{~cm}^{-1}$, respectively. The broad peak at $3310 \mathrm{~cm}^{-1}$ [Fig. 2a (G-TA)] in the spectra is associated with $\mathrm{OH}$ groups attached to TA, which demonstrating the absorbance of TA on graphene. Therefore, the characteristic peaks of G-TA come from TA noncovalently absorbed on graphene via strong physical interaction, which is acknowledged to
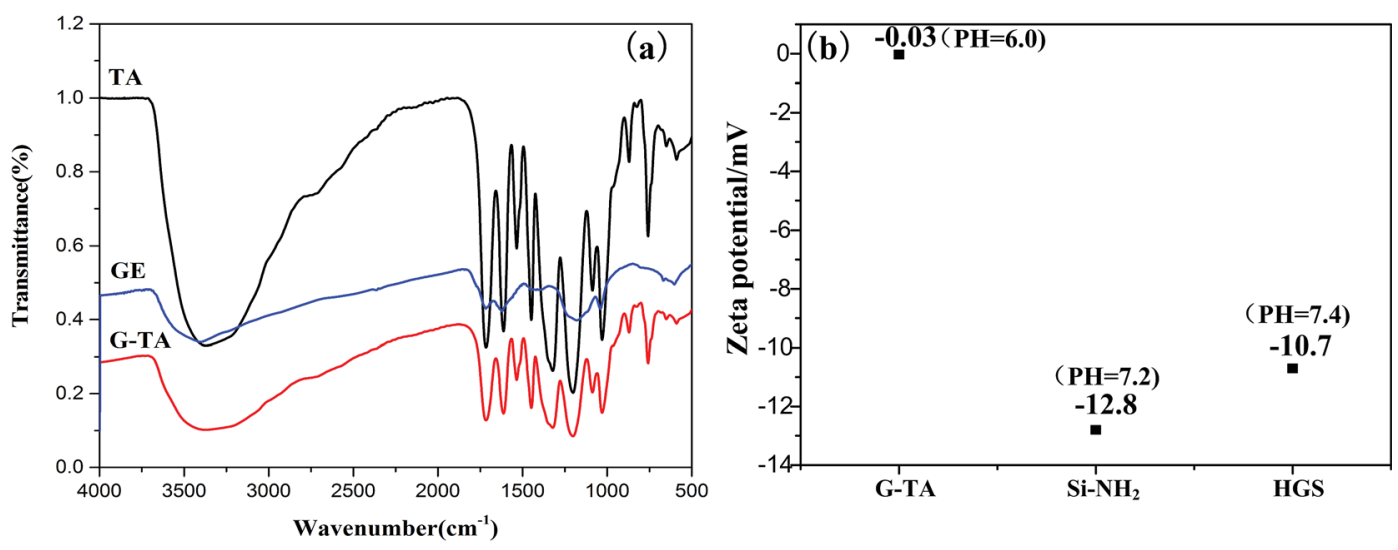

Fig. 2 (a) FTIR spectra of graphene (GE), TA and G-TA; (b) zeta potentials of G-TA, Si-NH $\mathrm{NH}_{2}$ and H3GS. 


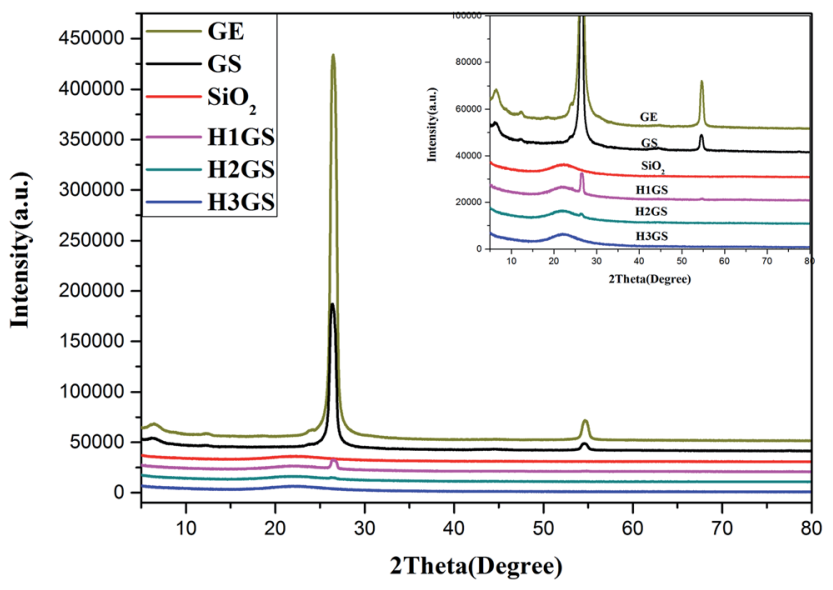

Fig. 4 XRD spectra of graphene (GE), $\mathrm{SiO}_{2}, \mathrm{GS}, \mathrm{H} 1 \mathrm{GS}, \mathrm{H} 2 \mathrm{GS}$ and H3GS.

be the $\pi-\pi$ interaction between plenty of aromatic rings of TA and graphene..$^{39-41}$ The zeta potentials of the G-TA, $\mathrm{Si}-\mathrm{NH}_{2}$ and H3GS dispersions respectively reach $-0.03 \mathrm{mV},-12.8 \mathrm{mV}$ and $-10.7 \mathrm{mV}$ (Fig. 2b), indicating the hybrid effect of graphene and $\mathrm{SiO}_{2}$ stems from the hydrogen bonding supplied by TA and primary amine rather than the electrostatic repulsion. Meanwhile, TGA analysis was used to quantitatively evaluate the hybrid fillers, as illustrated in Fig. 3. The hybrid fillers start to decomposition before $300{ }^{\circ} \mathrm{C}$ which is relative to the degradation of tannic acid and water. The weight loss in the temperature range of $300-600{ }^{\circ} \mathrm{C}$ manifests the condensation of the silanol groups on the surface of $\mathrm{SiO}_{2}$. The residual weight implies that the grafted $\mathrm{KH} 550$ content onto the $\mathrm{SiO}_{2}$ for $\mathrm{H} 1 \mathrm{GS}$, H2GS and H3GS are about $4.35 \mathrm{wt} \%, 4.46 \%$ and $4.71 \%$ respectively.

\subsection{Microstructure of hybrid filler system}

The XRD patterns of graphene, $\mathrm{SiO}_{2}$, GS and H1GS, H2GS, H3GS were shown in Fig. 4 . The major peaks at $2 \theta=26.2^{\circ}$ and $54.8^{\circ}$ are due to (002) and (004) of graphite and indicate the multilayer structure in graphene. The intensities of the major peak (002) and (004) monitor the disordered structure and defects inside graphene and hence provides implication for the dispersion status of hybrid filler. And that notes that the broadness of the major peak suggests the presence of small irregularity in the interplanar distances in (002). ${ }^{42}$ The GS sample demonstrates similar XRD diffraction peaks of graphene, even though the intensities of the major peak (002) and (004) are much weaker, and the broadness of (002) is much wider than that of graphene, which displaying the still existence of multilayer aggregation structure of graphene and poor
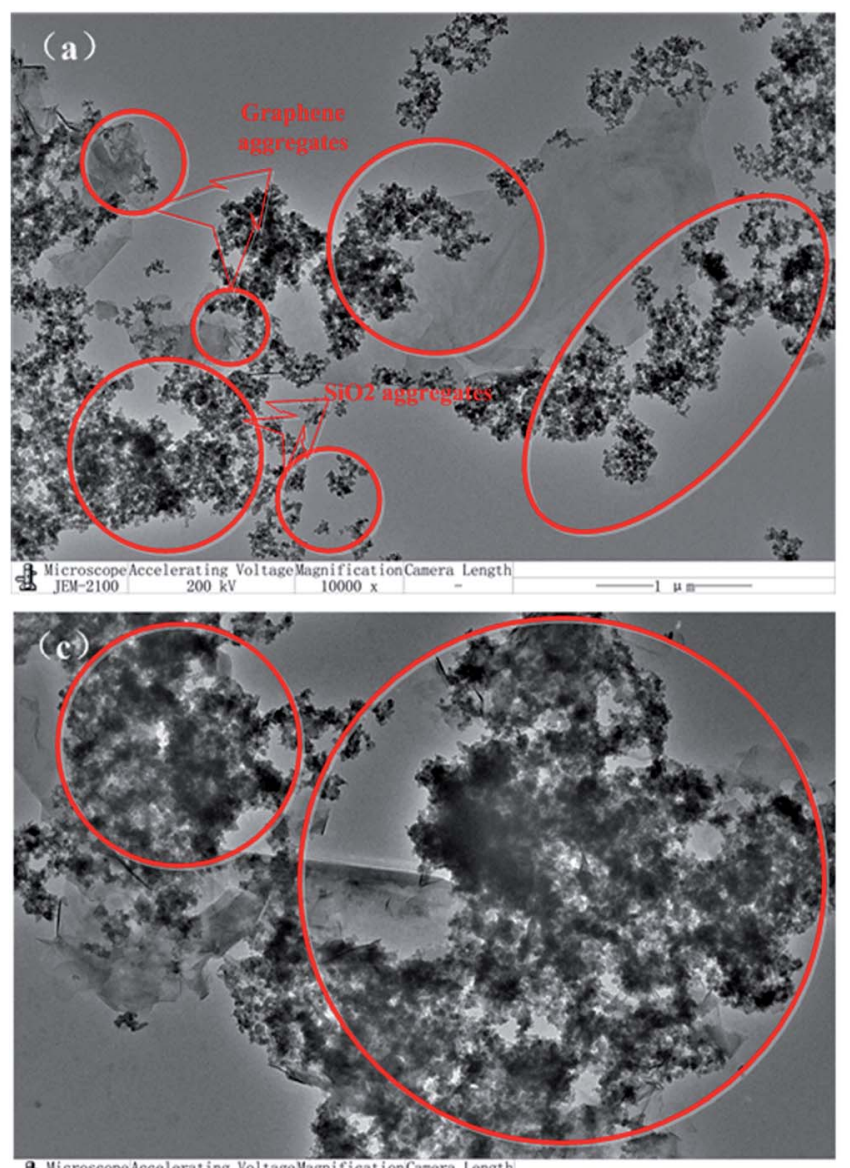

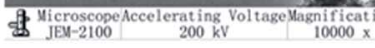

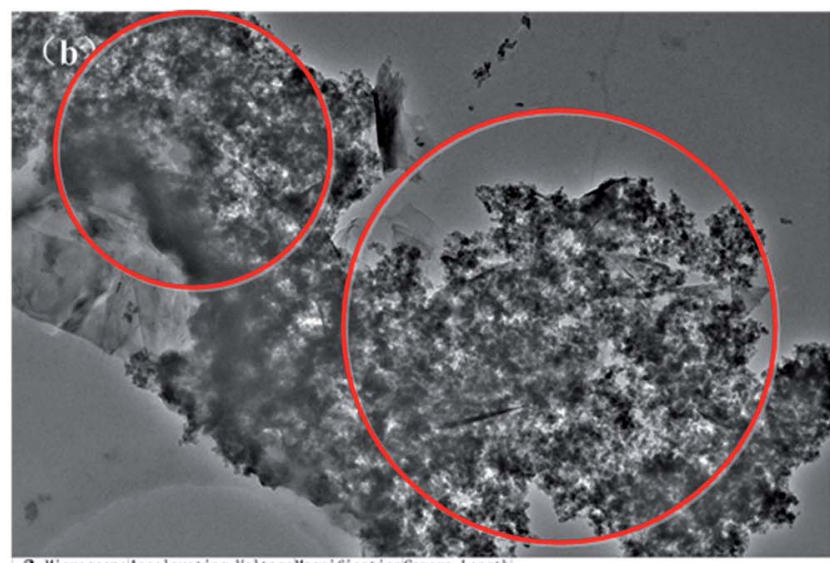

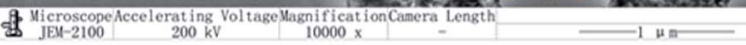

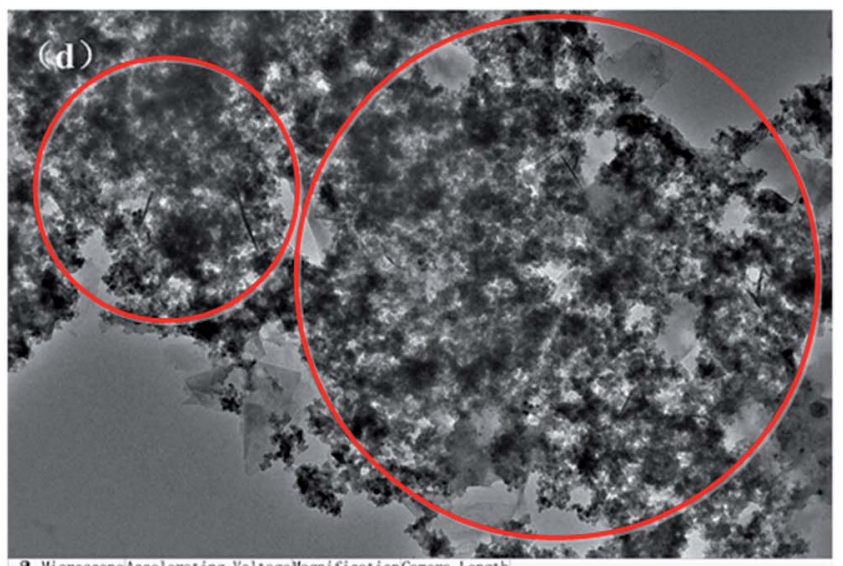

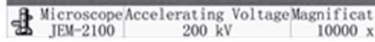

Fig. 5 TEM images of (a) GS, (b) H1GS, (c) H2GS and (d) H3GS. 
dispersion even after van der Waals force hybridization process. The XRD diffraction peaks (002) and (004) corresponding to graphene cannot be seen in H1GS, H2GS, and H3GS, indicating that the disaggregation of graphene and the thickness of graphene is less than $3 \mathrm{~nm} .{ }^{43}$ Moreover, it indicates higher hybridization on the surface of hybrid fillers are detected, most likely due to hydrogen bonding interaction between T-GA and $\mathrm{Si}-\mathrm{NH}_{2}$. Furthermore, the vanishment of the peaks (002) and (004) of H1GS, H2GS, H3GS is also indicative of a strong interfacial interaction between graphene and $\mathrm{SiO}_{2}$. In our study, this is probably because the $\mathrm{Si}-\mathrm{NH}_{2}$ nanoparticles hinder the graphene nanosheets from restacking, disrupt the ordered lamellar structure, and accordingly result in the vanishment of the diffraction peaks of graphene through hydrogen bonding self-assembly hybrid effect.

To further demonstrate the microscopic distribution state of hybrid fillers, TEM images as depicted in Fig. 5. H1GS, H2GS, and H3GS (Fig. 5b-d) demonstrate that the $\mathrm{SiO}_{2}$ nanoparticles are uniformly decorated on the surface of the graphene and well distributed throughout the surface of graphene for them. Moreover, the surface of H1GS, H2GS and H3GS is much rougher than that of GS (Fig. 5a). And that there is the more uniform distribution density of $\mathrm{SiO}_{2}$ and much higher surface roughness of hybrid fillers with higher silane coupling agent levels. Compared with GS, H1GS, H2GS and H3GS revealed the covering of entire graphene sheet by coating due to hydrogen bonding interaction. However, along with the wrinkles and edges of graphene, the $\mathrm{SiO}_{2}$ nanoparticles of GS (Fig. 5a) are only attached to the graphene nanosheets. It is because that unmodified $\mathrm{SiO}_{2}$ is easier to form weak van der Waals force hybridization interactions with unmodified graphene along the wrinkles and edges of graphene. After earliest attaching of a small amount of $\mathrm{SiO}_{2}$ nanoparticles in these areas, the rest of nanoparticles tend to form agglomeration within these regions. Thus, in GS sample with weak van der Waals force, graphene is barely covered with $\mathrm{SiO}_{2}$ particles (Fig. 5a) along with phase separation from $\mathrm{SiO}_{2}$. It is important to note that the hydrogenbonding between TA and silane coupling agent plays a role of surfactant to determine the interfacial interactions between graphene and $\mathrm{SiO}_{2}$ in promoting the formation of graphene$\mathrm{SiO}_{2}$ hybrid nanostructures. TEM micrographs confirm that HGS is few-layer graphene depicted in XRD results.
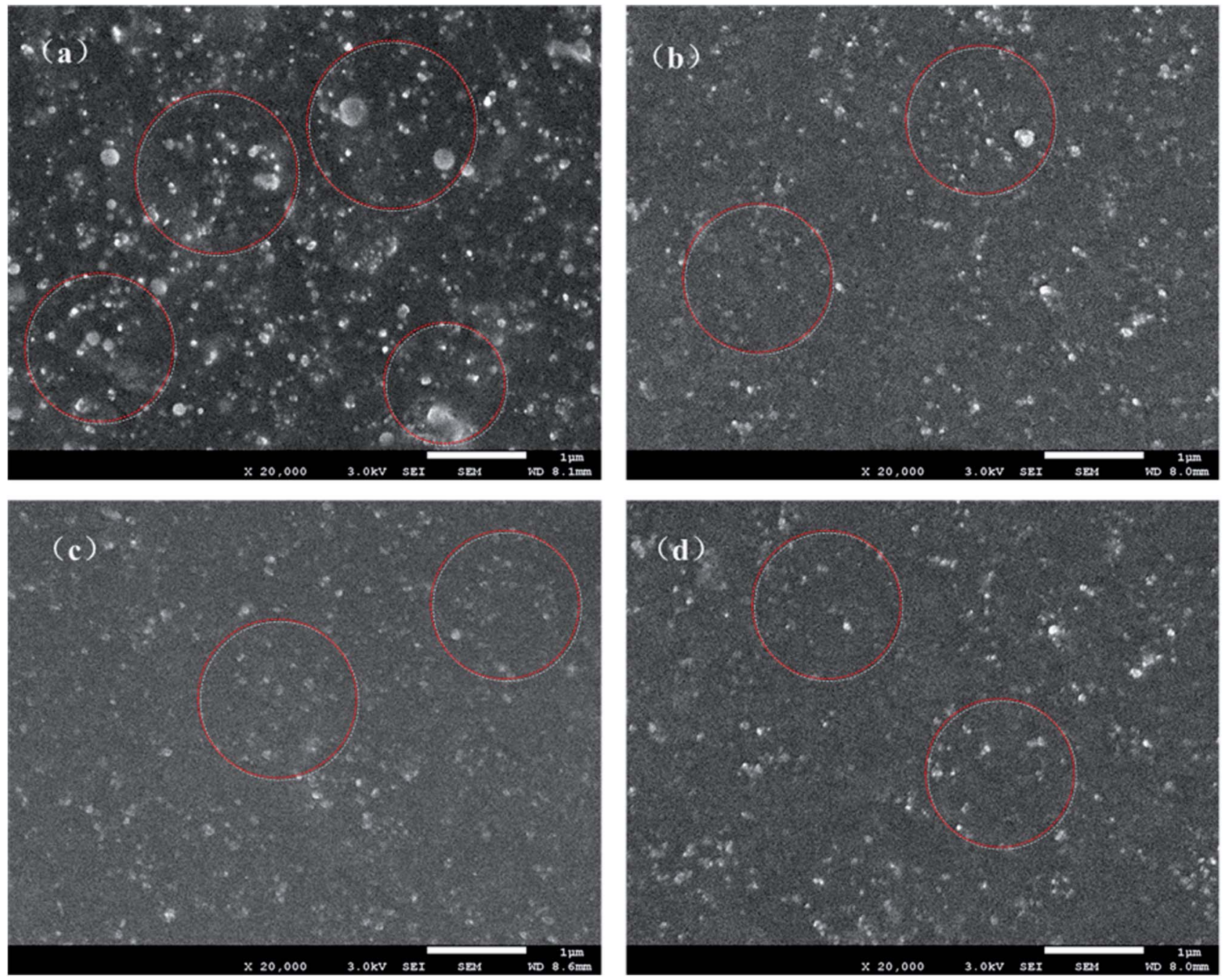

Fig. 6 SEM images of (a) GS@NR, (b) H1GS@NR, (c) H2GS@NR and (d) H3GS@NR composites. 


\subsection{Dispersion state of hybrid filler system in NR composites}

To characterize the microdispersion state of the fillers upon hybridization, SEM images of GS@NR and HGS@NR composites with different KH550/TA ratios are shown in Fig. 6. Even after sonication for a long time, a van der Waals force hybrid filled system (GS) cannot form a uniform distribution in NR matrix in which large aggregates with several microns (as indicated by the red circle) in diameter and are exposed all around the fracture surface. This clearly demonstrates the poor filler dispersion and filler-polymer interaction in GS@NR composites. As for hydrogen bonding self-assembly hybrid fillers (HGS), the filler dispersion state and compatible state are significantly improved as shown in Fig. 6b-d. Evidently, HGS with a size of about hundreds of nanometer (as indicated by the red circles) disperses homogeneously in NR matrix. The dispersal state of HGS was improved with increasing the KH550/ TA ratio.

Moreover, from Fig. 6b-d, we can see clearly that the HGS@NR nanocomposites display smooth surface morphology. When the KH550/TA ratio increases, the roughness degree of HGS@NR nanocomposite becomes smaller, which contribute to the stable dispersion of HGS nanoparticles in NR matrix and good compatible of HGS nanoparticles with NR matrix due to the low surface energy of HGS through hydrogen bonding selfassembly hybridization. Hence, it's reasonable to believe that the significantly improved hybrid filler dispersion in NR matrix originated from the strong hydrogen bonding self-assembly interaction between graphene and $\mathrm{SiO}_{2}$. The synergistic intercalation between the graphene nanoplatelets and the spherical $\mathrm{SiO}_{2}$ can inhibit their re-agglomeration and form strong network architecture.

\subsection{Effect of hybrid filler network on the chain relaxation dynamics of NR composites}

The synergistic intercalation due to the formation of strong network architecture is demonstrated by dynamical mechanical analysis. The results of the measurements of storage modulus $\left(G^{\prime}\right)$, and loss factor $(\tan \delta)$ are given in Fig. 7. When nanoparticles are added to the polymer, as the content of nanoparticles increases, the material will gradually change from similar liquid state to similar solid state. In dynamic viscoelastic research, loss factor $(\tan \delta)$ is usually used to
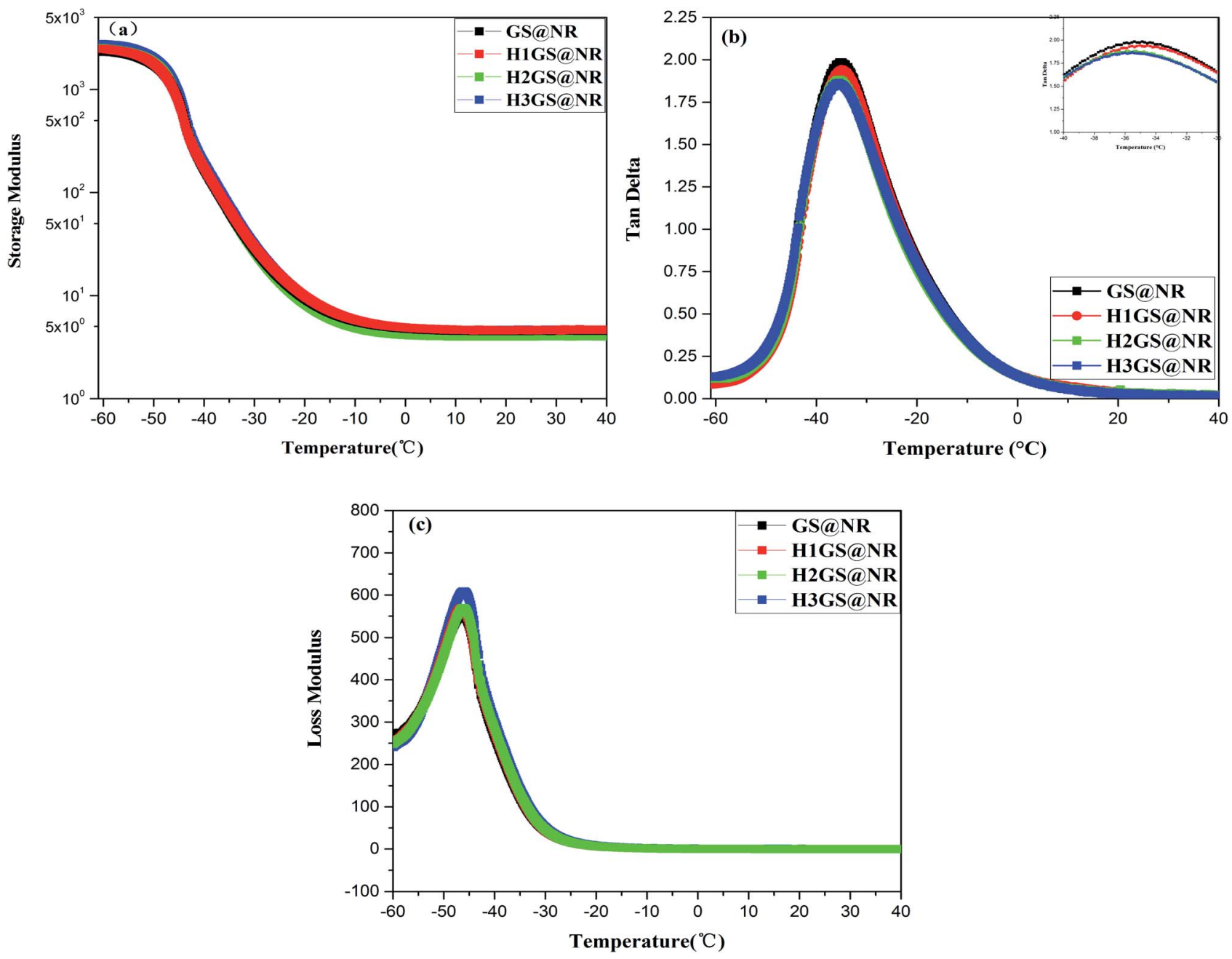

Fig. 7 (a) Storage modulus $\left(G^{\prime}\right)$, (b) loss factor ( $\tan \delta$ ) and (c) loss modulus $\left(G^{\prime \prime}\right)$ versus temperature for GS@NR and HGS@NR composites. 
characterize the interaction between filler and polymer as well as filler and filler. The viscoelasticity of hybrid nanocomposites was studied and the response signal of different loss factors was found in GS@NR and HGS@NR nanocomposites.

The $\tan \delta$ (Fig. 7a) of HGS@NR composites is much lower than that of GS@NR. Moreover, the lower the tan $\delta$ of HGS@NR composite is, the higher the content of the KH550/TA ratio is synergistic intercalation between the $\mathrm{SiO}_{2}$ and graphene can inhibit their re-agglomeration and form tight network architecture. Previous studies have shown that the incorporation of all kinds of nanocarbon gives rise to a decline in the peak value of tan $\delta .{ }^{\mathbf{4 4}}$ Hence, it's reasonable to believe that the significantly improved hybrid filler dispersion in NR matrix originated from the strong hydrogen bonding self-assembly interaction between $\mathrm{Si}-\mathrm{NH}_{2}$ and G-TA. Moreover, it's reasonable to suppose that a more efficient formation of hybrid filler network can generate an exclusive relaxation dynamics of polymer chains. The confinement effect on the NR matrix by graphene- $\mathrm{SiO}_{2}$ hybrid filler network can also be evaluated by storage modulus (Fig. 7b). It should be noted that, the larger increases in $G^{\prime}$ are attained in the HGS@NR over the entire temperature range, as compared with GS@NR. This finding can be explained by fact that the enhanced constrained region in the HGS@NR can be in favor of a very efficient load transfer from the matrix to HGS hybrid filler. That is, the increased fraction of the constrained region can markedly contribute to improving the performance of NR composites.

Rubber Processing Analyzer is also employed to evaluate the effect of the filler network on the thermal relaxation of NR chains as shown in Fig. 8. Fig. 8c depicts the strain-dependent $\tan \delta$ curves of NR composites with different fillers. The peak value of $\tan \delta$ tends to decrease with increasing HGS filler content. Moreover, the values for the HGS@NR composites are much higher than those for the GS@NR at the same strain. Such results suggest that the enhanced interfacial interaction between HGS and the matrix can effectively prompt the
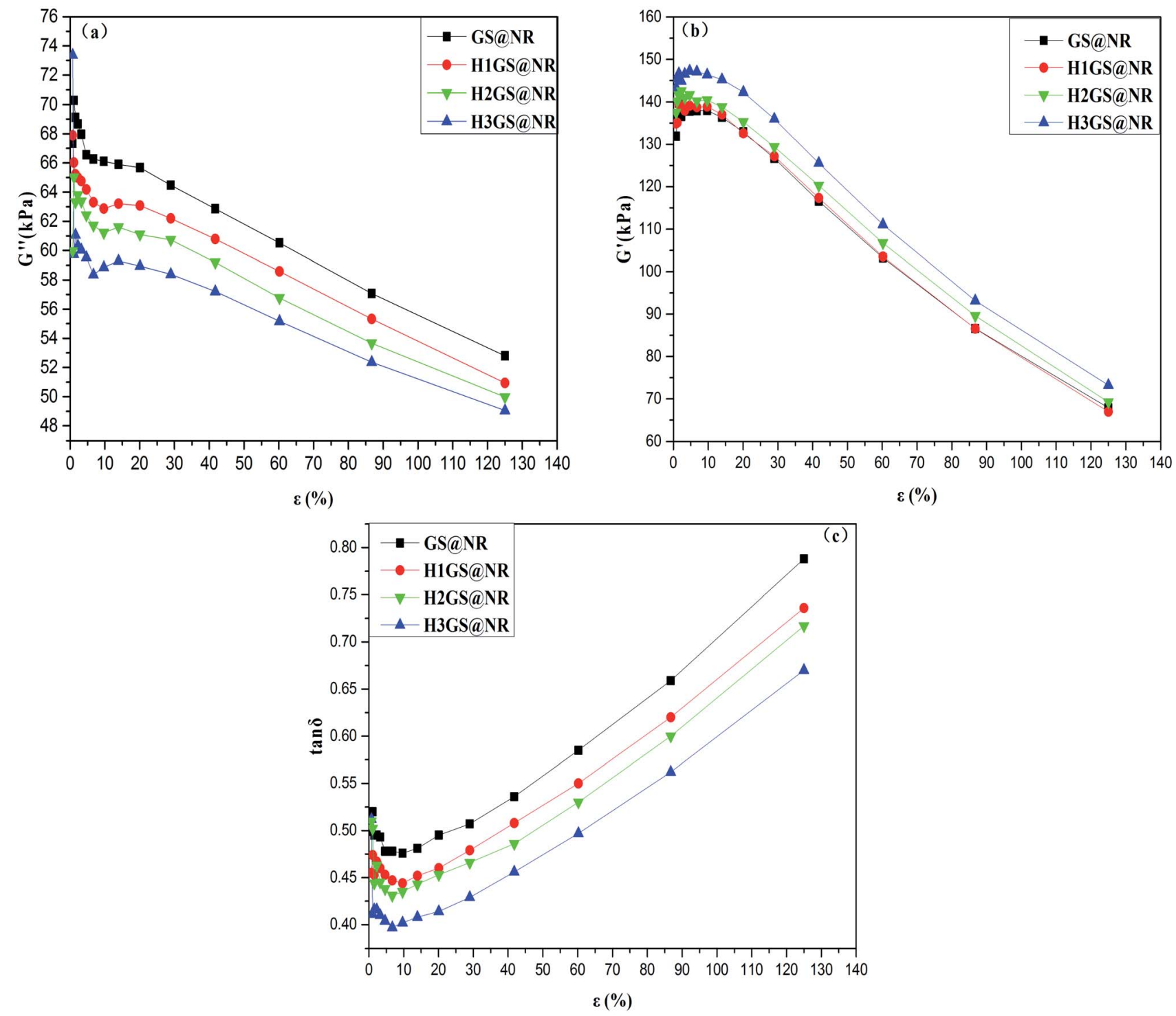

Fig. 8 (a) Strain-dependent loss modulus, (b) storage modulus and (c) $\tan \delta$ curves of GS@NR, H1GS@NR, H2GS@NR and H3GS@NR composites. 

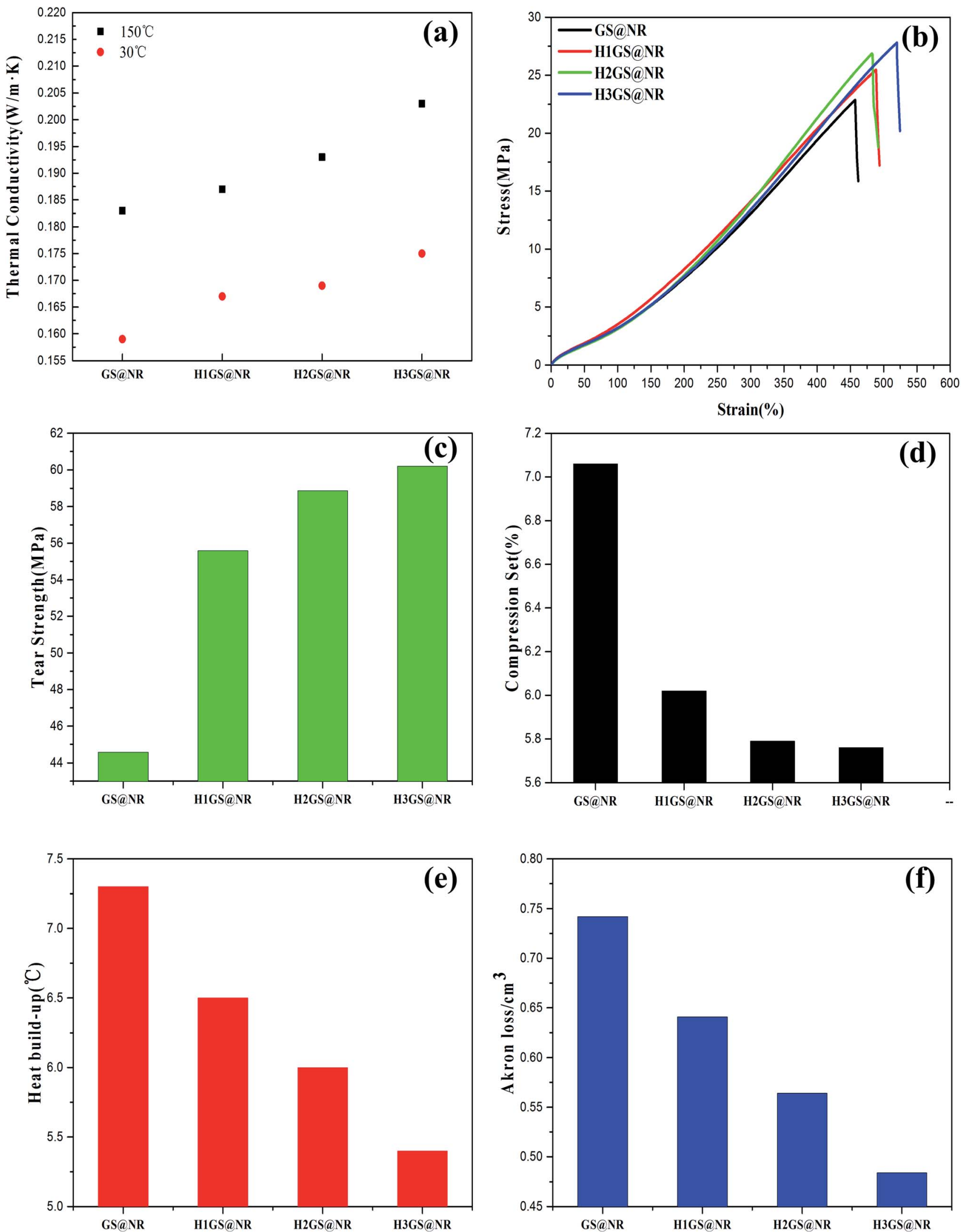

Fig. 9 (a) Thermal conductivity of GS@NR and HGS aNR composites, (b) tensile strength of GS aNR and HGS aNR composites, (c) tear strength of GS@NR and HGS@NR composites, (d) compression set of GS@NR and HGS@NR composites, (e) compression temperature rise of GS@NR and HGS aNR composites, (f) abrasive resistance of GS@NR and HGS@NR composites. 
configurational constraints of the NR chains, improving the fraction of constrained region in the rubber composites. It's widely accepted that the peak value of $\tan \delta$ is a measurement of the energy dissipation in polymer composites during the mechanical-cyclic test. ${ }^{\mathbf{4 5 , 4 6}}$ Such energy dissipation is inversely proportional to the interfacial interaction between polymer and filler network which will substantially constrain and impair the mobility of polymer chains. ${ }^{47}$

The results of the measurements of loss modulus $\left(G^{\prime \prime}\right)$ (Fig. 8a) show that the linear viscoelastic region decreases slightly with the interfacial interaction between the polymer and the filler network becomes strong. Meanwhile, the presence of a rigid three-dimensional filler network in the rubber composites can be characterized by the non-linearity of the viscoelastic storage modulus (Fig. 8b) at small dynamic strain amplitudes, knowing as the Payne effect. ${ }^{48}$ The Payne effect declined as the HGS hybrid filler content increased, indicating a reduction in filler network intensity, which demonstrating a superior reinforcement capability of HGS hybrid filler. ${ }^{37}$

\subsection{Thermal and mechanical properties of NR composites}

Concerning with thermal conductivity, compared with GS@NR, this was found to be affected by hybridization forms, where hydrogen bonding self-assembly hybrid interaction resulted in a significant increase in thermal conductivity of composites attributes from the nearly complete connected graphene sheets (Fig. 9a). On the one hand, a certain part of evenly distributed $\mathrm{SiO}_{2}$ is used to bridge the graphene sheet gaps in the in-plane direction that enlarge the phonon transmission channel and benefit the phonon propagation, while the re-aggregation of $\mathrm{SiO}_{2}$ induces larger interfacial thermal resistance that further decreases the thermal conductivity of GS@NR. ${ }^{49}$ On the other hand, previous studies ${ }^{50-52}$ indicated that when graphene sheets are over stacked into a paper, its thermal conductivity greatly drops one order of magnitude due to the phonons leakage across the interface and the enhanced umklapp scattering of out-plane acoustic phonons. However, graphene layers in HGS hybrid fillers are intercalated by $\mathrm{SiO}_{2}$ particles. Graphene sheets are partly separated by $\mathrm{SiO}_{2}$ that effectively retards the strong graphene interlayer stacking induced by the strong $\pi-\pi$ interactions. Thus phonons transfer thermal energy in the strictly $2 \mathrm{D}$ channel with the interference from out-of-plane being eliminated. It also means that effective thermal conduction path of graphene can be formed. The performance of HGS@NR composites would, therefore, be superior to that of GS@NR. Furthermore, thermal conduction path of graphene is more accessible to create promptly with increasing the ratio of KH550 to TA.

The results obtained for the mechanical properties of the variously compounded samples are presented in Fig. 9b-f. The HGS@NR composites deal with effects of change in the ratio of $\mathrm{KH} 550$ to TA at a fixed ratio of $\mathrm{SiO}_{2}$ to graphene. It is clearly seen from the Fig. $9 \mathrm{~b}$ that the tensile strength range is large varying between a minimum of 22.73 MPa to a maximum of 27.59 MPa. It is also seen from Fig. 9c that the highest tear strength of 60.20 MPa is with H3GS@NR followed by H2GS@NR showing a value of $58.87 \mathrm{MPa}$. However, with the compound containing GS, the tear strength is just the value at $44.57 \mathrm{MPa}$. As for HSG@NR composites, namely H1GS, H2GS and H3GS, the compression set, compression heat, flexing resistance and abrasive resistance properties not only improve but vary within wide limits. So compared with GS@NR composite, the comprehensive mechanical properties for HGS@NR composites to judge interface interaction fitness of composites are all promoted. The reason can be explained through their physical structures, size, shape, surface area and anisotropy of their distribution of hybrid fillers in the polymer matrix. ${ }^{53}$ The formation of tight network architecture due to synergistic hydrogen bonding self-assembly can prompt hybrid fillers to disperse well in the polymer matrix and prevent the stress concentration effectively, improving physical properties comprehensively. Furthermore, the formation of a glassy interphase with orders of magnitude slower chain dynamics than that for bulk chains has been explicitly demonstrated in the synergistic hydrogen bonding self-assembly hybrid system. ${ }^{17}$ Therefore, besides improved dispersion upon hybridization, it is believed the formation of a glassy interphase is another crucial factor in governing the synergistic capability of hybrid composites, as the showed results in DMA (Fig. 7) and RPA (Fig. 8). It can be explained also that graphene- $\mathrm{SiO}_{2}$ hybrid filler by hydrogen bonding self-assembly interaction had higher surface roughness values than that after van der Waals force hybridization. ${ }^{54}$ Meanwhile, the surface roughness is much higher with increasing the ratio of KH550 to TA as shown in Fig. 4. The surface roughness of fillers plays an important role in governing interfacial interaction between fillers and polymer matrix. This can be explained by the significantly higher maximum contact pressures for rough surfaces, which are present at the surface asperities. ${ }^{55}$ During compounding, due to high contact pressure, the sharp and hard protruding surface asperities of the rough hybrid fillers cause considerable interfacial interaction, leading to unique dispersion in polymer matrix. The strain-stress curve also indicates the discrepancy in toughness among the four nanocomposites. Here toughness is defined by the area of strain-stress curve which represents the absorbing energy without fracturing. H1GS@NR, H2GS@NR and H3GS@NR lead to improved toughness compared to GS@NR. Moreover, with increasing the ratio of KH550 to TA, it exhibits a significant increase in toughness. This is attributed to the improved dispersion and strong interface interaction between HGS and NR upon hydrogen bonding self-assembly hybridization. This leads to higher energy absorption and higher toughness.

\section{Conclusion}

In conclusion, a novel method for fabricating graphene- $\mathrm{SiO}_{2}$ hybrid filler through hydrogen bonding self-assembly interaction has been demonstrated. The $\mathrm{SiO}_{2}$ nanoparticles are uniformly decorated on the surface of the graphene and are well distributed throughout the surface of graphene. The formation of tight network architecture due to synergistic hydrogen bonding self-assembly intercalation effect between silane 
coupling agents modified $\mathrm{SiO}_{2}$ and TA modified graphene can prompt hybrid fillers to disperse well in the polymer matrix and prevent the stress concentration effectively, improving comprehensive performances. An effective thermal conduction path of graphene for HGS@NR can be formed to dramatically improve thermal property of composites. The superior synergistic hydrogen-bonding interaction can make the filler-rubber interfacial interaction strongly, which, in turn, contributes to the significant enhancement in the mechanical performances of composites by the incorporation of graphene- $\mathrm{SiO}_{2}$ hybrid filler into NR matrix. Also, it was noted that HGS has a higher reinforcing effect than those of GS. Particularly, the tensile strength and tear strength for H3GS@NR are dramatically increased by about $21.4 \%$ and $35.0 \%$ as compared with those of GS@NR, respectively.

\section{Conflicts of interest}

There are no conflicts to declare.

\section{Acknowledgements}

The authors gratefully acknowledge the financial support from National Natural Science Foundation of China [grant numbers 51603111, 51703111 and 51703109] Shandong Provincial Natural Science Foundation, China [grant numbers ZR2017BEM011, 2018GGX102015 and ZR2015PE021], Project of Shandong Province Higher Educational Science and Technology Program [J16LA06 and J17KA012], and Foundation of Key Laboratory of Rubber-Plastics, Ministry of Education/ Shandong Provincial Key Laboratory of Rubber-Plastics, Qingdao University of Science and Technology [No. KF2017005].

\section{References}

1 K. E. Prasad, B. Das, U. Maitra, U. Ramamurty and C. N. R. Rao, Extraordinary synergy in the mechanical properties of polymer matrix composites reinforced with 2 nanocarbons, Proc. Natl. Acad. Sci. U. S. A., 2009, 106, 13186-13189.

2 M. Shtein, R. Nadiv, M. Buzaglo, K. Kahil and O. Regev, Thermally conductive graphene-polymer composites: size, percolation, and synergy effects, Chem. Mater., 2015, 27, 2100-2106.

3 S. Gong, W. Cui, Q. Zhang, A. Cao, L. Jiang and Q. Cheng, Integrated ternary bioinspired nanocomposites via synergistic toughening of reduced graphene oxide and double-walled carbon nanotubes, ACS Nano, 2015, 9(12), 11568-11573.

4 C. Y. Tang, L. X. Xiang, J. X. Su, K. Wang, C. Y. Yang, Q. Zhang and $\mathrm{Q}$. Fu, Largely improved tensile properties of chitosan film via unique synergistic reinforcing effect of carbon nanotube and clay, J. Phys. Chem. B, 2008, 112(13), 38763881.

5 P. Weng, Q. Wei, Z. Tang, T. Lin and B. Guo, The influence of molybdenum disulfide nanoplatelets on the dispersion of nano silica in natural rubber composites, Appl. Surf. Sci., 2015, 359(30), 782-789.

6 S. Wan, Y. Li, J. Peng, H. Hu, Q. Cheng and L. Jiang, Synergistic toughening of graphene oxide-molybdenum disulfide-thermoplastic polyurethane ternary artificial nacre, ACS Nano, 2015, 9(1), 708-714.

7 M. K. Shin, B. Lee, S. H. Kim, J. A. Lee, G. M. Spinks, S. Gambhir, G. G. Wallace, M. E. Kozlov, R. H. Baughman and S. J. Kim, Synergistic toughening of composite fibres by self-alignment of reduced graphene oxide and carbon nanotubes, Nat. Commun., 2012, 3, 650-658.

8 J. J. Li, L. S. Shao, L. H. Yuan and Y. H. Wang, A novel strategy for making poly(vinyl alcohol)/reduced graphite oxide nanocomposites by solvothermal reduction, Mater. Des., 2014, 54, 520-525.

9 B. Ahmadi-Moghadam, M. Sharafimasooleh, S. Shadlou and F. Taheri, Effect of functionalization of graphene nanoplatelets on the mechanical response of graphene/ epoxy composites, Mater. Des., 2015, 66, 142-149.

10 M. C. Liu, Y. X. Duan, Y. Wang and Y. Zhao, Effect of graphene nanoplatelets on coefficient of thermal expansion of polyetherimide composite, Mater. Des., 2014, 53, 466-474.

11 S. Kumar, S. Raj, E. Kolanthai, A. K. Sood, S. Sampath and K. Chatterjee, Chemical functionalization of graphene to augment stem cell osteogenesis and inhibit biofilm formation on polymer composites for orthopedic applications, ACS Appl. Mater. Interfaces, 2015, 7, 3237-3252.

12 A. A. Vasileiou, M. Kontopoulou and A. Docoslis, A nonhydrogen bonding self-assembly compatibilization approach to improve the filler dispersion and properties of polyethylene/graphene composites, ACS Appl. Mater. Interfaces, 2014, 6, 1916-1925.

13 S. Yuezeng, L. Shuang, W. Dongqing, Z. Fan, L. Haiwei, G. Pengfei, C. Chong and F. Xinliang, Two-Dimensional Carbon-Coated Graphene/Metal Oxide Hybrids for Enhanced Lithium Storage, ACS Nano, 2012, 6(9), 8349-8356.

14 W. Donghai, C. Daiwon, L. Juan, Y. Zhenguo, N. Zimin, K. Rong, H. Dehong, W. Chongmin, V. S. Laxmikant, Z. Jiguang, A. A. Ilhan and L. Jun, Self-assembled $\mathrm{TiO}_{2}-$ graphene hybrid nanostructures for enhanced Li-ion insertion, ACS Nano, 2009, 3(4), 907-914.

15 W. Jinzuan, L. Ping, H. Yanshan, J. Jianzhong, H. Sheng, W. Dongqing and F. Xinliang, An ionic self-assembly approach towards sandwich-like graphene $/ \mathrm{SnO}_{2} /$ graphene nanosheets for enhanced lithium storage, RSC Adv., 2014, 4, 57869-57874.

16 C. T. Vincent, C. Li-Min, J. A. Matthew, K. W. Jonathan, N. Kurt, B. K. Richard and Y. Yang, Low-temperature solution processing of graphene-carbon nanotube hybrid materials for high-performance transparent conductors, Nano Lett., 2009, 9(5), 1949-1955.

17 W. Siwu, Z. Liqun, W. Peijin, Y. Zhijun, T. Zhenghai and G. Baochun, Correlating synergistic reinforcement with chain motion in elastomer/nanocarbon hybrids composites, Soft Matter, 2016, 12(33), 6885-7064. 
18 A. R. Mahdavian, M. Ashjari and A. B. Makoo, Preparation of poly(styrene-methyl methacrylate) $/ \mathrm{SiO}_{2} \quad$ composite nanoparticles via emulsion polymerization. an investigation into the compatibilization, Eur. Polym. J., 2007, 43(2), 336-344.

19 J. Lee, C. K. Hong, S. Choe and S. E. Shim, Synthesis of polystyrene/silicon dioxide composite particles by soap-free emulsion polymerization using positively charged colloidal silicon dioxide, J. Colloid Interface Sci., 2007, 310(1), 112-120.

20 P. Hajji, L. David, J. F. Gerard, J. P. Pascault and G. Vigier, Synthesis, structure, and morphology of polymer-silicon dioxide hybrid nanocomposites based on hydroxyethyl methacrylate, J. Polym. Sci., Part B: Polym. Phys., 1999, 37(22), 3172-3187.

21 M. J. Percy, J. I. Amalvy, D. P. Randall and S. P. Armes, Synthesis of vinyl polymer-silicon dioxide colloidal nanocomposites prepared using commercial alcoholic silicon dioxide sols, Langmuir, 2004, 20(6), 2184-2190.

$22 \mathrm{H}$. Zou, S. S. Wu and J. Shen, Polymer/silicon dioxide nanocomposites: preparation, characterization, properties, and applications, Chem. Rev., 2008, 108(9), 3893-3957.

23 S. D. Bhagat, Y. H. Kim, K. H. Suh, Y. S. Ahn, J. G. Yeo and J. H. Han, Superhydrophobic silicon dioxide aerogel powders with simultaneous surface modification, solvent exchange and sodium ion removal from hydrogels, Microporous Mesoporous Mater., 2008, 112, 504-509.

24 J. M. Ramos-Fernández, C. Guillem, A. Lopez-Buendía, M. Paulis and J. M. Asua, Synthesis of poly-(ba-co-mma) latexes filled with $\mathrm{SiO}_{2}$ for coating in construction applications, Prog. Org. Coat., 2011, 72(3), 438-442.

25 M. M. Jalili, S. Moradian, H. Dastmalchian and A. Karbasi, Investigating the variations in properties of 2-pack polyurethane clear coat through separate incorporation of hydrophilic and hydrophobic nano-silicon dioxide, Prog. Org. Coat., 2007, 59, 81-87.

26 Y. Z. Chen, Z. P. Zhang, J. Yu and Z. X. Guo, Poly(methyl methacrylate)/silicon dioxide nanocomposite fibers by electrospinning, J. Polym. Sci., Part B: Polym. Phys., 2009, 47(12), 1211-1218.

27 X. C. Zhang, Y. Z. Chen, J. Yu and Z. X. Guo, Thermoplastic polyurethane/silicon dioxide nanocomposite fibers by electrospinning, J. Polym. Sci., Part B: Polym. Phys., 2011, 49(23), 1683-1689.

28 J. M. Xue, C. H. Tan and D. Lukito, Biodegradable polymersilicon dioxide xerogel composite microspheres for controlled release of gentamicin, J. Biomed. Mater. Res., Part B, 2006, 78(2), 417-422.

29 B. Silvestri, G. Luciani, A. Costantini, F. Tescione and F. Branda, In-situ sol-gel synthesis and characterization of bioactive pHEMA/SiO $\mathrm{Si}_{2}$ blend hybrids, J. Biomed. Mater. Res., Part B, 2009, 89(2), 369-378.

30 C. Pandis, A. Spnoudaki, A. Kyritsis, P. Pissis, J. C. R. Hernandez, J. L. G. Ribelles and M. M. Pradas, Water sorption characteristics of poly(2-hydroxyethyl acrylate)/silicon dioxide nanocomposite hydrogels, $J$. Polym. Sci., Part B: Polym. Phys., 2011, 49(9), 657-668.
31 M. N. Xiong, L. M. Wu, S. X. Zhou and B. You, Preparation and characterization of acrylic latex/nano-SiO $\mathrm{S}_{2}$ composites, Polym. Int., 2002, 51(8), 693-698.

32 A. Schmid, J. Tonnar and S. P. Armes, A new highly efficient route to polymer-silicon dioxide colloidal nanocomposite particles, Adv. Mater., 2008, 20(17), 3331-3336.

33 A. Guyard, J. Persello, J. P. Boisvert and B. Cabane, Relationship between the polymer/silicon dioxide interaction and properties of silicon dioxide composite materials, J. Polym. Sci., Part B: Polym. Phys., 2006, 44(7), 1134-1146.

34 T. Mahrholz, J. Stängle and M. Sinapius, Quantitation of the reinforcement effect of silicon dioxide nanoparticles in epoxy resins used in liquid composite moulding processes, Composites, Part A, 2009, 40(3), 235-243.

35 H. Zhang, L. C. Tang, Z. Zhang, K. Friedrich and S. Sprenger, Fracture behaviours of in situ silicon dioxide nanoparticlefilled epoxy at different temperatures, Polymer, 2008, 49(17), 3816-3825.

36 N. Nanying, W. Minglu, Z. Jing, Z. Liqun and T. Ming, Simultaneously improved actuated performance and mechanical strength of silicone elastomer by reduced graphene oxide encapsulated silicon dioxide, Int. J. Smart Nano Mater., 2015, 6(4), 251-267.

37 L. Yong, L. Shuqi, P. Jian and L. Lan, The fille-rubber interface and reinforcement in styrene butadiene rubber composites with graphene/silica hybrids: a quantitative correlation with the constrained region, Composites, Part A, 2016, 86, 19-30.

38 Z. Haiyan, L. Yingxi and Z. Danfeng, Graphene nanosheet/ silicone composite with enhanced thermal conductivity and its application in heat dissipation of high-power lightemitting diodes, Curr Appl Phys, 2016, 16(12), 1695-1702.

39 N. Yan, G. Buonocore, M. Lavorgna, S. Kaciulis, S. K. Balijepalli, Y. H. Zhan, H. S. Xia and L. Ambrosio, The role of reduced graphene oxide on chemical, mechanical and barrier properties of natural rubber composites, Compos. Sci. Technol., 2014, 102, 74-81.

40 R. J. Liao, Z. H. Tang, T. F. Lin and B. C. Guo, Scalable and versatile graphene functionalized with the mannich condensate, ACS Appl. Mater. Interfaces, 2013, 5, 2174-2181.

41 Z. J. Yang, J. Liu, R. J. Liao, G. W. Yang, X. H. Wu, Z. H. Tang, B. C. Guo, L. Q. Zhang, Y. Ma, Q. H. Nie and F. Wang, Rational design of covalent interfaces for graphene/ elastomer nanocomposites, Compos. Sci. Technol., 2016, 132, 68-75.

42 R. Kumar, N. Kushwaha and J. Mittal, Superior, rapid and reversible sensing activity of graphene-SnO hybrid film for low concentration of ammonia at room temperature, Sens. Actuators, B, 2017, 244(9), 243-251.

43 C. Rao, K. Biswas, K. Subrahmanyam and A. Govindaraj, Graphene, the new nanocarbon, J. Mater. Chem., 2009, 19(17), 2457-2469.

44 M. J. Wang, Effect of polymer-filler and filler-filler interactions dynamic properties of filled vulcanizates, Rubber Chem. Technol., 1998, 71(3), 520-589. 
45 P. Maier and D. Göritz, Molecular interpretation on the Payne effect, KGK, Kautsch. Gummi Kunstst., 1996, 49, 18-21.

46 J. G. Meier and M. Klüppel, Carbon black networking in elastomers monitored by dynamic mechanical and dielectric spectroscopy, Macromol. Mater. Eng., 2008, 293, 12-38.

47 M. J. Wang, Effect of filler-elastomer interaction on tire tread performance part I, Kautsch. Gummi Kunstst., 2007, 60, 438443.

48 E. B. D. da Rochaa, F. N. Linharesa, C. F. S. Gabrielb, A. M. F. de Sousaa and C. R. Guimarães Furtadoa, Stress relaxation of nitrile rubber composites filled with a hybrid metakaolin/carbon black filler under tensile and compressive forces, Appl. Clay Sci., 2018, 151, 181-188.

49 C. T. Hsieh, C. E. Lee, Y. F. Chen, J. K. Chang and H. S. Teng, Thermal conductivity from hierarchical heat sinks using carbon nanotubes and graphene nanosheets, Nanoscale, 2015, 7(44), 18663-18670.
50 P. T. Araujo, M. Terrones and M. S. Dresselhaus, Defects and impurities in graphene like materials, Mater. Today, 2012, 15(3), 98-109.

$51 \mathrm{~W}$. Chen and L. Yan, Preparation of graphene by a lowtemperature thermal reduction at atmosphere pressure, Nanoscale, 2010, 2(4), 559-563.

52 J. H. Seol, I. Jo, A. L. Moore, L. Lindsay, Z. H. Aitken and M. T. Pettes, Two-dimensional phonon transport in supported graphene, Science, 2010, 328(5975), 213-216.

53 X. Feng, L. Yinong, X. Yan and L. Yunfei, Controllable morphology evolution of electrodeposited $\mathrm{ZnO}$ nano/ micro-scale structures in aqueous solution, Mater. Des., 2009, 30(5), 1704-1711.

54 K. P. Shaha, Y. T. Pei, D. Martinez-Martinez and J. T. M. De Hosson, Influence of hardness and roughness on the tribological performance of TiC/a-C nanocomposite coatings, Surf. Coat. Technol., 2010, 205, 2624-2632.

55 G. W. Stachowiak and A. W. Batchelor, Engineering Tribology, Elsevier science publishers, 1993. 